\title{
Prevalence of proline racemase/ hydroxyproline epimerase gene in human brucella isolates in Iran
}

\author{
Iman Hashemifar ${ }^{1}$, Faramarz Masjedian Jazi ${ }^{1}$, Abbas Yadegar ${ }^{2}$, Nour Amirmozafari ${ }^{1 *}$
}

Received: 6 Feb 2017

Published: 7 Sep 2017

\begin{abstract}
Background: Human brucellosis is a zoonotic disease caused by Brucella melitensis, Brucella abortus, and Brucella suis. Brucella causes a chronic disease, which subverts the immune defense system of their hosts. In this study, the prevalence of an important Brucella virulence determinant, PrpA, which can modulate immune response, was determined in human isolates.

Methods: Polymerase chain reaction (PCR) assay was standardized and applied to 37 isolates obtained from patient's specimens. Primers for $\operatorname{prp} A$ gene were designed and evaluated using bioinformatic tools. DNA sequencing was performed for further verification. Results: In the 37 Brucella isolates (31 Brucella melitensis and 6 Brucella abortus), 32 (86.4\%) carried prpA gene.

Conclusion: Presence of prpA gene in most isolates indicates the high prevalence of this gene among Iranian isolates and emphasizes its role in pathogenicity of this organism.
\end{abstract}

Keywords: Brucella species, Brucellosis, Proline Racemase, PrpA

Copyright $@$ Iran University of Medical Sciences

Cite this article as:Hashemifar I, Masjedian Jazi F, Yadegar A, Amirmozafari N. Prevalence of proline racemase/hydroxy proline epimerase gene in human brucella isolates in Iran. Med J Islam Repub Iran. 2017(7 Sep);31:57.https://doi.org/10.14196/mjiri.31.57

\section{Introduction}

Brucella, a Gram negative coccobacillus, is responsible for brucellosis disease in domestic and wild animals and is transmittable to human hosts. Although humans are not the main sources of infection, the disease causes socioeconomic problems in many countries (1). Broad spectrum of mammalians is at risk of becoming infected with Brucella. Humans are mainly infected by Brucella melitensis, Brucella abortus, and Brucella suis (2-3). Human brucellosis is transmitted through several routs such as ingestion of contaminated dairy products, inhalation, and direct contact with infected animal tissues; however, person to person transmission is extremely rare (4-5). The disease is febrile and debilitating for human hosts, with particular problems and constitutional symptoms (6). Additionally, brucellosis is a chronic and persistent infection with a capacity of becoming granulomatous (7).

Pathogenicity in Brucella and other intracellular organisms such as Leishmania spp., Trypanosomes and Salmonella typhi depends on survival and replication of the organism inside the host cell. These pathogens develop mul-

Corresponding author:DrNourAmirmozafari,amirmozafari@yahoo.com

1. Department of Microbiology, School of Medicine, Iran University of Medical Sciences, Tehran, Iran.

2. Foodborne and Waterborne Diseases Research Center, Research Institute for Gastroenterology and Liver Diseases, Shahid Beheshti University of Medical Sciences, Tehran, Iran. tiple approaches to subvert the host immune responses. The ability to hide and survive in host cells leads to establishment of a chronic infection (8-9). Accordingly, Brucella utilizes numerous factors such as type IV secretion system (VirB), cyclic $\beta 1$, 2-glucans, and LPS to manipulate the host's immune system. Identification of new putative factors has opened many doors for better understanding of pathogenicity (10).

Brucella PrpA (Proline Racemase Protein A), homologous to a proline racemase with mitogenic activity in the human protozoan parasite Trypanosoma cruzi, is a Tindependent B lymphocyte mitogen and a potent IL-10 inducer required for the establishment of chronicity and the early immune suppression observed in mice after infection (10). PrpA uses NMM-IIA (nonmuscular myosin IIA) for attachment to macrophages to activate lymphoproliferation (11). Although PrpA has been described as immunomodulatory molecule in several pathogens (12$14)$, there had been no information on the prevalence of PrpA in Brucella species in Iran. In the present study, a

$\uparrow$ What is "already known" in this topic:

PrpA as an immunomdulatory molecule activates IL-10 and stimulates B cell replication. Organism such as Brucella requires PrpA to establish chronic infections.

$\rightarrow$ What this article adds:

High prevalence of $\operatorname{prp} A$ gene in human Brucella isolates may increase the virulence capacity among Iranian isolates of $B$. melitensis and B. abortus. 
Table 1. PCR primer sequence used for amplification of the Brucella prpA gene.

\begin{tabular}{lccc}
\hline Target gene & Primer designation & $\begin{array}{c}\text { Oligonucleotide sequence } \\
\left(5^{\prime}-3^{\prime}\right)\end{array}$ & PCR product (bp) \\
\hline PrpA & PrpA-F & AACCTCAATGGATCGACC & 672 \\
& PrpA-R & ACGGTCGATAGCCTTGTC & \\
\hline
\end{tabular}

PCR assay was developed to detect prpA gene that was applied to $37 \mathrm{~B}$. melitensis and B. abortus isolates obtained from patients in cities of Tehran, Arak and Hamadan in Iran.

\section{Methods}

\section{Bacterial strains}

From a total of 37 isolates, $31 \mathrm{~B}$. melitensis and $6 \mathrm{~B}$. abortus were identified based on bacteriological tests such as colony morphology, Gram staining, oxidase, catalase, $\mathrm{CO}_{2}$ growth, $\mathrm{H}_{2} \mathrm{~S}$ production, and dye tolerance such as basic fushin and thionin.

\section{DNA preparation}

A loopful of colonies of each isolate on Brucella agar plates was picked and suspended in $200 \mu \mathrm{L}$ of distilled water. After vortexing, the suspension was boiled for 5 minutes, and $50 \mu \mathrm{L}$ of the supernatant was collected after spinning at $14000 \mathrm{rpm}$ for 10 minutes. The DNA concentration of the boiled extracts was determined with a spectrophotometer.

\section{PCR assay}

PCR amplifications were performed in a final volume of
$25 \mu \mathrm{L}$ in PCR tubes. The reaction mixtures consisted of 2 $\mu \mathrm{L}$ of the DNA template, $1 \mu \mathrm{L}$ of each primer, $8 \mu \mathrm{L}$ of mastermix (Taq DNA polymerase Mastermix Mix Red, $\mathrm{MgCl}_{2}$, Amplicon), and the total volume was adjusted to $25 \mu \mathrm{L}$ using distilled deionized water. PCR program for amplification of $\operatorname{prp} A$ consisted of initial denaturation at $94^{\circ} \mathrm{C}$ for 4 minutes, 30 cycles of application with denaturation at $94^{\circ} \mathrm{C}$ for 1 minute, annealing at $58^{\circ} \mathrm{C}$ for 1 minute, extension at $72^{\circ} \mathrm{C}$ for 1 minute, and final extension at $72^{\circ} \mathrm{C}$ for 10 minutes. Electrophoresis of PCR products was performed on $1.5 \%$ agarose gels using 100-bp DNA ladder as molecular size marker. Gels were visualized under UV and documented using Uvitec System DOC008.XD (EEC).

\section{Primer designation and DNA sequencing}

The nucleotide sequence of Brucella prpA gene was obtained from $B$. melitensis $16 \mathrm{M}$ chromosome II complete sequence (AE008918.1) in NCBI GenBank database. Specific primer set was designed based on pairwise and multiple sequence alignment for the corresponding gene using CLC Sequence Viewer Version 6.8.2. The primer sequences and their amplicon size are demonstrated in Table 1 .

\begin{tabular}{|c|c|c|c|c|c|}
\hline NUMBER & GENDER & SPECIMEN TYPE & BRUCELLA SPECIES & STRAIN & PROVINCE/CITY \\
\hline 1 & Female & $C S F$ & B. melitensis & $1-A$ & Arak \\
\hline 2 & Female & CSF & B. melitensis & $2-A$ & Arak \\
\hline 3 & Male & Blood & B. melitensis & $3-A$ & Arak \\
\hline 4 & Male & Blood & B. melitensis & $4-A$ & Arak \\
\hline 5 & Female & Blood & B. abortus & $5-A$ & Arak \\
\hline 6 & Male & $C S F$ & B. melitensis & $12-A$ & Arak \\
\hline 7 & Male & Blood & B. abortus & $16-A$ & Arak \\
\hline 8 & Male & Blood & B. melitensis & $19-A$ & Arak \\
\hline 9 & Male & Blood & B. melitensis & $20-A$ & Arak \\
\hline 10 & Female & Blood & B. melitensis & $18-H$ & Hamadan \\
\hline 11 & Male & Blood & B. melitensis & $22-H$ & Hamadan \\
\hline 12 & Female & Blood & B. melitensis & $33-H$ & Hamadan \\
\hline 13 & Male & Blood & B. melitensis & $34-H$ & Hamadan \\
\hline 14 & Male & Blood & B. melitensis & $35-H$ & Hamadan \\
\hline 15 & Female & Blood & B. melitensis & $39-H$ & Hamadan \\
\hline 16 & Male & Blood & B. melitensis & $40-H$ & Hamadan \\
\hline 17 & Male & Blood & B. abortus & $46-H$ & Hamadan \\
\hline 18 & Male & Blood & B. melitensis & $48-H$ & Hamadan \\
\hline 19 & Male & Blood & B. melitensis & $54-H$ & Hamadan \\
\hline 20 & Male & Blood & B. melitensis & $1-T$ & Tehran \\
\hline 21 & Female & Blood & B. melitensis & $2-T$ & Tehran \\
\hline 22 & Female & Blood & B. abortus & $3-T$ & Tehran \\
\hline 23 & Female & Blood & B. melitensis & $5-T$ & Tehran \\
\hline 24 & Male & $C S F$ & B. abortus & $11-T$ & Tehran \\
\hline 25 & Female & Blood & B. abortus & $18-T$ & Tehran \\
\hline 26 & Male & Blood & B. melitensis & $19-T$ & Tehran \\
\hline 27 & Male & Blood & B. melitensis & $21-T$ & Tehran \\
\hline 28 & Female & Blood & B. melitensis & $22-T$ & Tehran \\
\hline 29 & Male & CSF & B. melitensis & $24-T$ & Tehran \\
\hline 30 & Male & Blood & B. melitensis & $27-T$ & Tehran \\
\hline 31 & Male & Blood & B. melitensis & $29-T$ & Tehran \\
\hline 32 & Male & Blood & B. melitensis & $30-T$ & Tehran \\
\hline 33 & Female & Blood & B. melitensis & $31-T$ & Tehran \\
\hline 34 & Female & $C S F$ & B. melitensis & $32-T$ & Tehran \\
\hline 35 & Female & CSF & B. melitensis & $33-T$ & Tehran \\
\hline 36 & Male & CSF & B. melitensis & $385-T$ & Tehran \\
\hline 37 & Male & Blood & B. melitensis & $14508-T$ & Tehran \\
\hline
\end{tabular}


Table 3. Distribution prpA genes among 37 human Brucella isolates

\begin{tabular}{ccc}
\hline Virulence gene & & $\begin{array}{c}\text { Human isolates } \\
(\mathrm{n}=37)\end{array}$ \\
\cline { 2 - 4 } & B. melitensis & B. abortus \\
$(\mathrm{n}=31)$ & $(\mathrm{n}=6)$ \\
prpA & $31(100)$ & $1(16.7)$ \\
\hline
\end{tabular}

The amplified fragment of $\operatorname{prp} A$ gene was purified using Silica Bead DNA Gel Extraction Kit (Thermo Scientific, USA). Sequencing was performed on both strands using an automated sequencer system (ABI 3730xl DNA Analyzer). DNA sequences were edited by Chromas Lite Version 2.5.1 (Technelysium Pty Ltd, Australia) and BioEdit Version 7.2.5 (Hall, 1999).

\section{Results}

From a total of 37 isolates, 31(83.7\%) B. meltensis and 6 (16.3) B. abortus were identified from 29 blood and 8 CSF human samples. Of the patients, $23(62 \%)$ were male and $14(38 \%)$ were female. Detailed information on specimen type, Brucella species type, and areas of sample collection are presented in Table 2. As expected, prp $A$ gene assay produced an amplicon of $672 \mathrm{bp}$ (Fig. 1).

In the current study, all $B$. melitensis isolates had prpA gene; however, just one of the six B. abortus isolates was positive for this gene (Table 3). Analysis of the sequenced gene with Chromas software and blast in the NCBI (National Center for Biotechnology Information) site showed the same DNA sequences; therefore, all the PCR assay results were confirmed.

\section{Discussion}

Brucella has an amazing ability to adapt to hosts' cellular atmosphere and evade immune responses. Other organisms which cause chronic diseases such as Mycobacteium tuberculosis, Salmonella spp, and Trypanosoma cruzi use

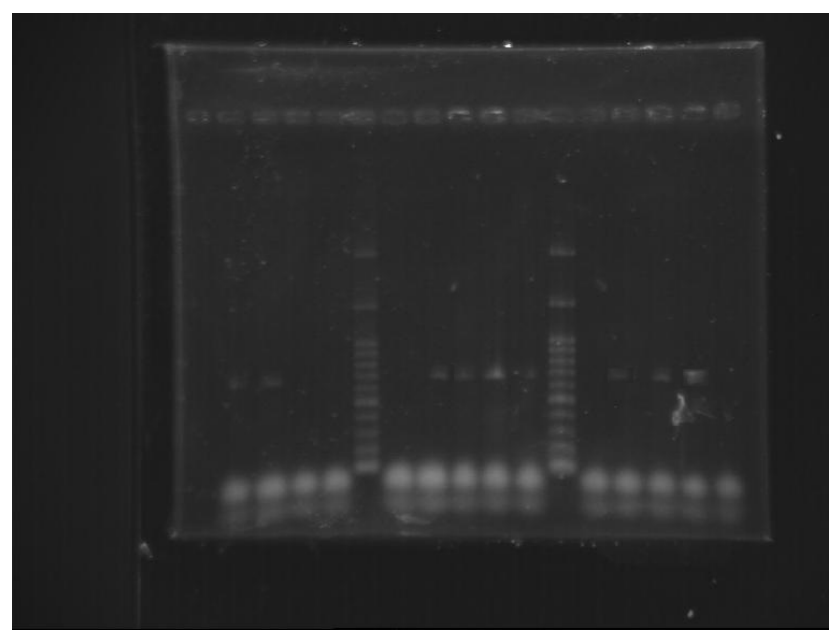

Fig. 1. Representative PCR products of Brucella prpA gene from human strains of B. melitensis and B. abortus. Lanes M, DNA Ladder Mix; Lanes $2,3,7,8,9,10,12,13$ are Brucella melitensis strains positive for prpA, Lane 14 Brucella abortus strain positive for prpA, Lanes 4,5,6,11,15 are Brucella abortus strains negative for prpA. the same mechanism to reach their replication niche (15). Although little is known about the molecular mechanisms of Brucella virulence factors, numerous putative factors have been identified (16).

The present study aimed at identifying $B$. melitensis and $B$. abortus strains, which were carriers of prpA gene. Our results confirmed the presence of prp $A$ gene in $32(86.4 \%)$ $B$. melitensis and B. abortus isolates collected from human patient specimens. Interestingly, 5 out of $6 \mathrm{~B}$. abortus isolates lacked this gene, which is not completely consistent with the result of Spera et al. (10). Our findings revealed the presence of prpA gene in human isolates of Brucella $(100 \%$ B. melitensis, and $16.6 \%$ B. abortus)and not in animal isolates, which may be responsible for variations in results. It can be concluded that the present gene is more frequent in $B$. melitensis strains compared with $B$. abortus strains in Iran; however, there is no warrant for expression of the gene.

Proline racemase protein, a homodimeric enzyme, was initially identified in Clostridium sticklandii protobacterium; however, a eukaryotic proline racemase was first isolated from Trypanosoma cruzi(TcPRAC), the causative agent of Chagas disease (17). According to Goytia et al., Proline racemase function is similar to hydroxy proline epimerase activity as a lymphocyte mitogen (18). This enzyme is capable of converting L and D-proline enantiomers reversibly (19); D-amino acids are often found in eukaryotes and bacterial cell walls (20). Proline racemase antibodies and inhibitor, and pyrrole-2-carboxylic acid

(PYC) exert influence on the infection of T. cruzi in vitro. PYC can also interfere in intracellular T. cruzi differentiation (19). PrpA in Brucella is a molecular virulence factor, which can put the host's immune system in an anergic state (10).

\section{Conclusion}

The present study demonstrated a very high level of prpA gene presence in human Brucella isolates. The design of a PCR test to assess the presence of aforementioned gene was a first attempt to understand the mechanism of virulence, especially in Iranian isolates of Brucella melitensis and Brucella abortus. For further understanding of prpA genetic epidemiology, similar studies on animal isolates may be required.

\section{Acknowledgments}

This study was financially supported by a research grant (No. 25996-30-02-94) for a M.Sc. thesis in Iran University of Medical Sciences (Tehran, Iran), for which we are very grateful. 


\section{Conflict of Interests}

The authors declare that they have no competing interests.

\section{References}

1. Pappas G. The changing Brucella ecology: novel reservoirs, new threats. Int J Antimicrob Agents.2010;36:1:8-11.

2. Mantur BG,Amarnath SK,Shinde RS. Review of clinical and laboratory features of human brucellosis. Indian $\mathrm{J}$ Med Microbiol.2007;25:188-202.

3. Godfroid J,Cloeckaert A,Liautard JP,Kohler S,Fretin D,Walravens K, et al. From the discovery of the Malta fever's agent to the discovery of a marine mammal reservoir, brucellosis has continuously been a reemerging zoonosis. Vet Res.2005;36:313-326.

4. Mesner O,Riesenberg K,Biliar N,Borstein E,Bouhnik L,Peled N, et al. The many faces of human-to-human transmission of brucellosis: congenital infection and outbreak of nosocomial disease related to an unrecognized clinical case. Clin Infect Dis.2007;45:e135-40.

5. Baldi PC,Giambartolomei GH. Pathogenesis and pathobiology of zoonotic brucellosis in humans. Rev Sci Tech.2013;32:117-25.

6. Franco MP,Mulder M,Gilman RH,Smits HL. Human brucellosis. Lancet Infect Dis.2007; 7:775-786.

7. HasanjaniRoushan MR,Mohrez M,SmailnejadGangi SM,SoleimaniAmiri MJ,Hajiahmadi M. Epidemiological features and clinical manifestations in 469 adult patients with brucellosis in Babol, Northern Iran. Epidemiol Infect.2004;132:1109-1114.

8. Kaufmann SH. Intracellular pathogens: living in an extreme environment. Immunol Rev.2011;240:5-10.

9. Spera JM,Herrmann CK,Roset MS,Comerci DJ,Ugalde JE. A Brucella virulence factor targets macrophages to trigger B-cell proliferation. J Biol Chem.2013;288:20208-16.

10. Spera JM, Ugalde JE,Mucci J, Comerci DJ, Ugalde RA.A B lymphocyte mitogen is a Brucellaabortus virulence factor required for persistent infection. ProcNatlAcadSci USA. 2006;103:16514-16519.

11. Coutinho L,Ferreira MA,Cosson A,Batista MM,Batista Dda G,Minoprio P. Inhibition of Trypanosomacruziprolineracemase affects host-parasite interactions and the outcome of in vitro infection. MemInst Oswaldo Cruz.2009;104:1055-62.

12. Wang Y,Chen Z,Qiu Y,Ke Y,Xu J,Yuan X. Identification of Brucellaabortus virulence proteins that modulate the host immune response. Bioengineered.2012;3:303-5.

13. Byndloss MX,Tsolis RM. Brucella spp. virulence factors and immunity. Annu Rev AnimBiosci. 2015;4:111-127.

14. Atluri VL,Xavier MN,de Jong MF,den Hartigh AB,Tsolis RM. Interactions of the human pathogenic Brucella species with their hosts. Annu Rev Microbiol.2011;65:523-41.

15. Delrue RM, Martinez-Lorenzo M, Lestrate P, Danese I, Beilarz V, Mertens P, et al. Identification of Brucella spp. genes involved in intracellular trafficking. Cell Microbiol. 2001;3:487-497.

16. de Jong MF,Tsolis RM. Brucellosis and type IV secretion. Future Microbiol.2012 Jan;7:47-58.

17. Coatnoan N,Berneman A,Chamond N,Minoprio P. Prolineracemases: insights into Trypanosomacruzi peptides containing D-proline. MemInst Oswaldo Cruz.2009;104:1:295-300.

18. Goytia M,Chamond N,Cosson A,Coatnoan N,Hermant D,Berneman, et al. Molecular and Structural Discrimination of ProlineRacemase and Hydroxyproline-2-Epimerase from Nosocomial and Bacterial Pathogens. PLoS ONE. 2007;2:e885.

19. Chamond N, Grégoire C, Coatnoan N, Rougeot C, Freitas-Junior LH,da Silveira JF, et al. Biochemical characterization of prolineracemases from the human protozoan parasite Trypanosomacruzi and definition of putative protein signatures. J Biol Chem.2003 2;278:1548415494.

20. Buschiazzo A,Goytia M, Schaeffer F, Degrave W, Shepard, W, Grégoire C, et al. Crystal structure, catalytic mechanism, and mitogenic properties of Trypanosomacruziprolineracemase. Proc Natl Acad Sci USA. 2006;103:1705-1710. 